\title{
The value of including thalamic atrophy as a clinical trial endpoint in multiple sclerosis
}

Menno M. Schoonheim, MSc, PhD, and Olga Ciccarelli, MD, PhD, FRCP

Neurology ${ }^{\circledR}$ 2018;90:677-678. doi:10.1212/WNL.0000000000005279

Multiple sclerosis (MS) features a substantial white matter (WM) pathology in the brain, which manifests as focal lesions and reduced volume (or atrophy) compared with healthy controls. In addition, extensive gray matter (GM) atrophy is strongly prevalent in MS and highly clinically relevant but can be difficult to measure, especially in a clinical setting. ${ }^{1}$ Recent work has shown clear patterns of GM atrophy in patients with $\mathrm{MS}^{2}$ that are focused on brain network hubs, i.e., regions that are strongly connected with the rest of the brain. These areas are important for cognitive decline and disability progression and include the thalamus ${ }^{3}$ and other regions belonging to the default-mode ${ }^{2,4}$ and motor networks. ${ }^{2}$ There has been a recent surge of interest in the thalamus, with some hope that thalamic atrophy and its associated dysfunction may be a treatment target of especially high potential ${ }^{3}$ because thalamic atrophy can be measured relatively easily. The value of including thalamic atrophy as a trial endpoint in clinical trials with disease-modifying treatment in MS is emerging. ${ }^{5}$

In this issue of Neurology ${ }^{\circledR}$, Gaetano et al. ${ }^{6}$ present their post hoc analysis of 2 randomized placebo-controlled phase III trials (FTY720 Research Evaluating Effects of Daily Oral Therapy in Multiple Sclerosis [FREEDOMS] and FREEDOMS II) of fingolimod, a second-line treatment option for MS in most countries. Fingolimod consists of a sphingosine-1-phosphate receptor modulator that sequesters lymphocytes in lymph nodes, preventing their entry into the brain. Fingolimod reduces the annual rate of brain volume loss in patients with relapsingremitting MS by approximately one-third relative to that in individuals receiving placebo or intramuscular interferon beta-1a. ${ }^{7}$ This new analysis of the FREEDOMS and FREEDOMS II trials describes the effect of fingolimod in reducing regional volume loss, thereby extending and completing previous reports.

Gaetano et al. confirmed that fingolimod reduces the overall brain volume loss by about onethird $(31.7 \%)$ at a clinical dosage of $0.5 \mathrm{mg}$. In addition, it has an effect on reducing the deep GM volume loss by $14.5 \%$ and the thalamic volume loss by $26.1 \%$ over 2 years. No significant effect on cortical atrophy was detected. Baseline T2 lesion volumes predicted thalamic volume loss. A lower thalamic volume at baseline was associated with disability progression, regardless of treatment.

The results from this study are an important contribution to the development of MRI endpoints for clinical trials because they demonstrate that the added value of including regional measures such as thalamic volume as outcome measures in clinical trials is substantial. The addition of such regional volumes is especially beneficial if they show a faster rate of change than whole-brain volume loss and their measurement error is relatively small. This study suggests that reanalyses of existing datasets with newer analysis techniques are attractive and should be pursued.

The mechanism by which fingolimod reduces the volume loss in the deep GM and the thalamus in MS remains unclear. Lesions within the thalamus are not that common and do not correlate well with thalamic atrophy, ${ }^{8}$ suggesting that effects in other compartments such as the WM may be the causative factor for thalamic damage. The present article presents additional support for

\author{
Correspondence \\ Dr. Schoonheim \\ m.schoonheim@vumc.nl
}

\section{RELATED ARTICLE}

Fingolimod effect on gray matter, thalamus, and white matter in patients with multiple sclerosis

Page 686

From the Department of Anatomy and Neurosciences (M.M.S.), Amsterdam Neuroscience, MS Center Amsterdam, VU University Medical Center, the Netherlands; Department of Neuroinflammation (O.C.), UCL Institute of Neurology, University College London; and National Institute for Health Research (O.C.), University College London Hospitals Biomedical Research Centre, UK.

Go to Neurology.org/N for full disclosures. Funding information and disclosures deemed relevant by the authors, if any, are provided at the end of the editorial. 
this hypothesis; the strong correlation between thalamic volume loss and baseline T2 lesions suggests that structural disconnection is the cause of thalamic atrophy. Given that the thalamus is one of the most important hubs in our brain, the chance that WM lesions will affect tracts connected to the thalamus is considerable, inducing a progressive disconnection syndrome over time. This concept of a network-based neurodegeneration may explain the early presentation of thalamic atrophy, ${ }^{3}$ whereas the apparent later involvement of cortical areas and the subsequent acceleration of GM atrophy in progressive $\mathrm{MS}^{9}$ may be the result of a further exhaustion of the brain network, leading to an eventual network collapse. ${ }^{10}$

This study is one of the first to show a GM compartmentspecific treatment effect but should nonetheless be treated with caution. The primary drawback of the study lies in the use of cross-sectional techniques to determine longitudinal atrophy rates, which is an important problem likely to be alleviated with newer longitudinal analysis tools currently being developed. In addition, there is the lack of regional cortical GM measurements and an absolute increase in WM volume in fingolimodtreated patients only, which may be due to a bias in the imaging analysis algorithm or to biological factors.

Some key unanswered questions remain. Is an early network disconnection indeed the primary cause of thalamic neurodegeneration in MS? Will this thalamic damage lead to a subsequent cortical network collapse (with atrophy on MRI) and acceleration of GM atrophy over time? The possibility of slowing down neurodegeneration in MS is therefore of high interest and novel. Longitudinal imaging studies are needed to better understand the underlying mechanisms leading to thalamo-cortical neurodegeneration in MS and to identify whether thalamic atrophy is a suitable trial endpoint to be added to whole-brain atrophy measures.

\section{Study funding}

Dr. Schoonheim receives research support from the Dutch MS Research Foundation (13-820) and Amsterdam Neuroscience. Dr. Ciccarelli receives funding from the UK MS Society Rosetrees, National MS Society, and PMSA Trust, and her work is supported by the National Institute for Health Research, University College London Hospitals Biomedical Research Centre.

\section{Disclosure}

Dr. Schoonheim received consulting or speaking fees from ExceMed, Biogen, Sanofi-Genzyme, and Novartis and serves as an editorial board member of Frontiers in Neurology. Dr. Ciccarelli serves as a consultant for Biogen, Teva, SanofiGenzyme, Roche Pharma AG, and Novartis and is an associate editor of Neurology. Go to Neurology.org/ $\mathrm{N}$ for full disclosures.

\section{References}

1. Rocca MA, Battaglini M, Benedict RH, et al. Brain MRI atrophy quantification in MS: from methods to clinical application. Neurology 2017;88:403-413.

2. Steenwijk MD, Geurts JJ, Daams M, et al. Cortical atrophy patterns in multiple sclerosis are non-random and clinically relevant. Brain 2016;139:115-126.

3. Kipp M, Wagenknecht N, Beyer C, Samer S, Wuerfel J, Nikoubashman O. Thalamus pathology in multiple sclerosis: from biology to clinical application. Cell Mol Life Sci 2015;72:1127-1147.

4. Eshaghi A, Bodini B, Ridgway GR, et al. Temporal and spatial evolution of grey matter atrophy in primary progressive multiple sclerosis. Neuroimage 2014;86:257-264.

5. Filippi M, Rocca MA, Pagani E, et al. Placebo-controlled trial of oral laquinimod in multiple sclerosis: MRI evidence of an effect on brain tissue damage. J Neurol Neurosurg Psychiatry 2014;85:851-858.

6. Gaetano L, Häring DA, Radue EW, et al. Fingolimod effect on gray matter, thalamus, and white matter in patients with multiple sclerosis. Neurology 2018;90:e1324-e1332.

7. De Stefano N, Silva DG, Barnett MH. Effect of fingolimod on brain volume loss in patients with multiple sclerosis. CNS Drugs 2017;31:289-305.

8. van de Pavert SH, Muhlert N, Sethi V, et al. DIR-visible grey matter lesions and atrophy in multiple sclerosis: partners in crime? J Neurol Neurosurg Psychiatry 2016; 87:461-467.

9. Larochelle C, Uphaus T, Prat A, Zipp F. Secondary progression in multiple sclerosis: neuronal exhaustion or distinct pathology? Trends Neurosci 2016;39:325-339.

10. Schoonheim MM, Meijer KA, Geurts JJ. Network collapse and cognitive impairmen in multiple sclerosis. Front Neurol 2015;6:82. 


\section{Neurology}

The value of including thalamic atrophy as a clinical trial endpoint in multiple sclerosis Menno M. Schoonheim and Olga Ciccarelli

Neurology 2018;90;677-678 Published Online before print March 14, 2018 DOI 10.1212/WNL.0000000000005279

This information is current as of March 14, 2018

$\begin{array}{ll}\begin{array}{l}\text { Updated Information \& } \\ \text { Services }\end{array} & \begin{array}{l}\text { including high resolution figures, can be found at: } \\ \text { http://n.neurology.org/content/90/15/677.full }\end{array} \\ \text { References } & \begin{array}{l}\text { This article cites } 10 \text { articles, } 4 \text { of which you can access for free at: } \\ \text { http://n.neurology.org/content/90/15/677.full\#ref-list-1 }\end{array} \\ \text { Subspecialty Collections } & \begin{array}{l}\text { This article, along with others on similar topics, appears in the } \\ \text { following collection(s): } \\ \text { Multiple sclerosis } \\ \text { http://n.neurology.org/cgi/collection/multiple_sclerosis }\end{array} \\ & \begin{array}{l}\text { Information about reproducing this article in parts (figures,tables) or in } \\ \text { its entirety can be found online at: }\end{array} \\ \text { http://www.neurology.org/about/about_the_journal\#permissions } \\ \text { Information about ordering reprints can be found online: } \\ \text { heprints } & \text { http://n.neurology.org/subscribers/advertise }\end{array}$

Neurology ${ }^{\circledR}$ is the official journal of the American Academy of Neurology. Published continuously since 1951, it is now a weekly with 48 issues per year. Copyright () 2018 American Academy of Neurology. All rights reserved. Print ISSN: 0028-3878. Online ISSN: 1526-632X.

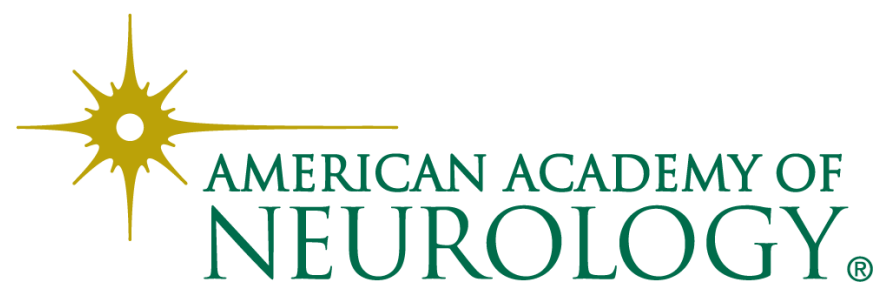

